\title{
Simulation Analysis of Sweet Pepper Harvesting Operations
}

\author{
Zohar Elkoby ${ }^{1}$, Bert van't Ooster ${ }^{2,3}$, and Yael Edan ${ }^{1}$ \\ ${ }^{1}$ Dept. of Industrial Engineering \& Management, Ben-Gurion University of the Negev, Israel \\ ${ }^{2}$ Wageningen University, Farm Technology Group, Wageningen, The Netherlands \\ ${ }^{3}$ Wageningen UR Greenhouse Horticulture, Wageningen, The Netherlands
}

\begin{abstract}
Greenhouse crop production requires extensive manual labor. The objective of this research is to analyze different work methods for harvesting in sweet pepper greenhouses. Operations research of harvesting work methods for a Dutch and Israeli sweet pepper greenhouse was performed. An existing discrete event simulation model on the crop handling processes inside a greenhouse, GWorkS, was used to simulate harvesting of sweet peppers in both countries. Results of simulation of one day showed that the model estimates harvesting time with an accuracy of $92 \%$ for NL data and $96 \%$ for IL data. The data analysis showed differences between the greenhouses in the existing harvesting procedures, logistic operations and data collection.
\end{abstract}

Keywords: Agriculture work methods, Simulation, Operations research, Pepper harvesting, Data Analysis.

\section{Introduction}

Greenhouse crop production requires extensive repetitive manual labor. A current problem in greenhouse horticulture is lack of human resources and high cost of human labor [4], [11]. Labor costs in greenhouse horticulture, constitute $29 \%$ and $25 \%$ of the production costs in the Netherlands [2] and in Israel (Israeli Central Bureau of Statistics) respectively. One solution is to improve labor efficiency. Work methods analysis is a commonly employed technique to improve production, operations management and increase efficiency [7]. In addition and as a complementary tool, simulation can be used to assess for cost-effectiveness, the effect of changing existing processes or the introduction of new processes in an actual system [9].

Advanced research has been applied to improve work methods in greenhouse horticulture for different crops such as sweet peppers [4], tomatoes [5], Gypsophila flowers [3], roses [11] using work methods analyses and simulation.

This paper focuses on operations research of harvesting work methods using a simulation model developed for sweet pepper harvesting processes in Israel and the Netherlands. The simulation model is based on a previous model developed for a different environment and crop: the GWorkS-rose model [11]. The focus of this paper is validating the GWorkS model for sweet pepper harvesting in two greenhouses from different countries. 


\section{Material and Methods}

\subsection{Company Characteristics and Data Acquisition}

\section{The Dutch Greenhouse}

The greenhouse's production area is approximately 8.6 hectares of red peppers separated into two different greenhouses. Each greenhouse has a main aisle with crops on both sides, organized within paths. Each greenhouse has four sectors of 72-80 paths with path length $115 \mathrm{~m}$. Not all workers of the greenhouse are qualified to perform all crop related tasks. The company uses electronic trolleys that has an adjustable height and is men-operated in the paths. Within a path, the trolley runs along a pipe rail system which is also used as a heating system.

The grower uses a SDF labour registration system (LRS) which records work hours, and enables work planning, tracking and tracing to analyse labour operations and worker performance. The LRS also registers the yield in each path. Automatic reports can be generated on every task done by the workers, on frequency of tasks and time required per task and day. The data was collected between the first week of 2012 (January 1st) and week 38 of 2013 (September 19th). Only the first greenhouse with 304 paths was simulated for testing and validation of the model.

\section{The Israeli Net House}

The net house's production area is approximately 2 hectares of red peppers separated into two different growing areas. One area is for growing peppers in the "Spanish" cultivation system and the other is in the "Dutch" cultivation system. The net house has a main aisle with crops on both sides, organized within paths. This research focus was on the "Dutch" cultivation area. This area has two sections with a total of 168 paths of $48 \mathrm{~m}$ length. The company uses hand-pushed trolleys to buffer the peppers harvested. During harvesting, the worker walks with the trolley in the path.

The grower does not use an automatic registration system, but he collects and fills Excel tables with the relevant data by himself. The data summarizes information about the yield and workers of the net house. The data was collected between the first week of 2010 and week 11 of 2014 (March $10^{\text {th }}$ ). For the model, only the second part of the greenhouse (the "Dutch" cultivation system) was simulated (168 paths) and compared to the whole season's data for this greenhouse area, from July $13^{\text {th }}$ to March $10^{\text {th }}$.

\subsection{Data Analysis}

The procedure performed in order to process the data was described by a Process Flow diagram (Fig. 1). Data was processed in Excel, using pivot tables and in Access using queries. 

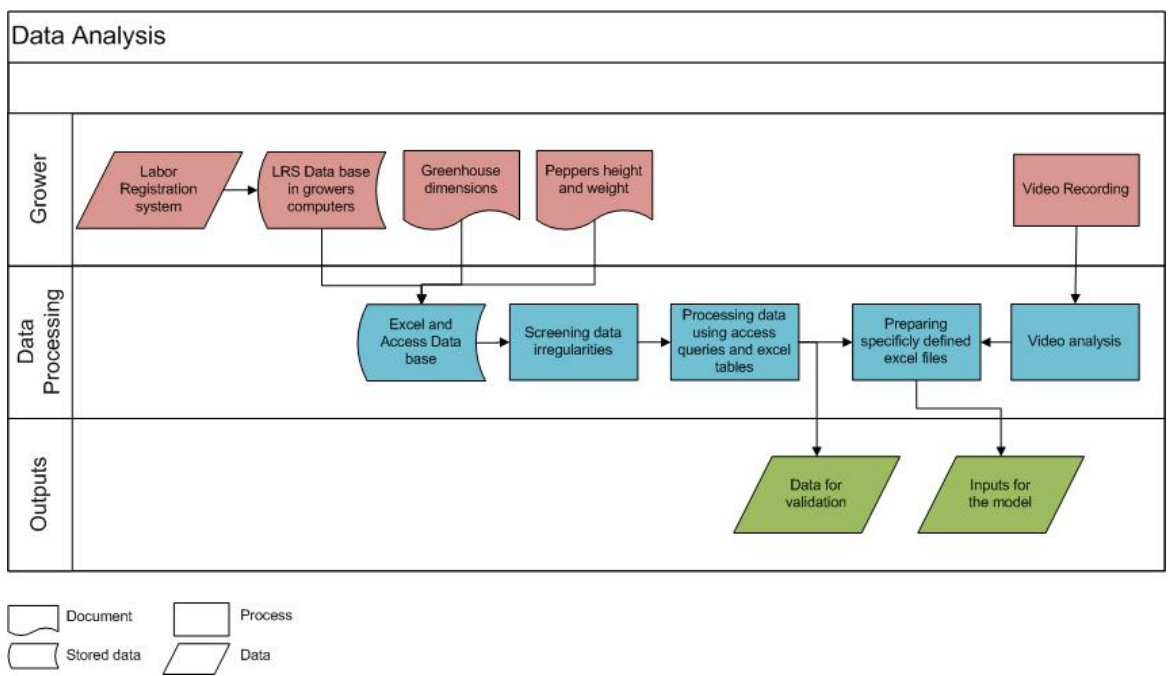

Fig. 1. Process flow diagram for stages of data analysis

The model inputs include: information regarding crop yield per day and per identifiable location, job frequencies, information about the resources of the greenhouse, and probability density function (pdf) parameters of the actions that constitute the harvesting process (Table 1). In order to prepare the pdf parameters video recordings were analyzed using Noldus Observer $\mathrm{XT}^{\circledR}([1],[10])$, which resulted in a series of

Table 1. Parameters of probability density functions (pdf) for sub actions of the harvest operation. The number of observations (n) is given and parameters $\mathrm{p} 1$ and $\mathrm{p} 2$.

For a normal distribution, $\mathrm{p} 1$ is mean and $\mathrm{p} 2$ is standard deviation, and for a lognormal distribution, $\mathrm{p} 1$ is $\mu$ and $\mathrm{p} 2$ is $\sigma$

\begin{tabular}{|l|l|l|l|l|l|l|}
\hline Name & Description & Green- & $\mathbf{N}$ & Pdf name & $\mathbf{P}_{\mathbf{1}}$ & $\mathbf{P}_{\mathbf{2}}$ \\
\hline house & & & & & &
\end{tabular}


timings of defined actions. The resulting distribution of these measured service times resembled the shape of a lognormal distribution as confirmed by Q-Q plots ([1]). The probability density function parameters were best-fit estimated using Matlab ([6]).

Measured average daily yield (per greenhouse section) was used as a model input. Yield was assigned to paths using a lognormal distribution with parameters estimated from mean and standard deviation between measured locations. Fruit dispersion was defined using uniform probability distributions for the $\mathrm{X}, \mathrm{Y}$ and $\mathrm{Z}$ coordinates within constraints that defined the space where fruits are harvested.

\subsection{Model Validation}

The GWorkS model was prepared to simulate each greenhouse according to its properties, work processes and resources and validated by analyzing a one day harvest. For the one day validation of the Dutch model, a run was performed on 25 paths (101125 ) of the Dutch greenhouse for September $26^{\text {th }} 2012$ in order to calibrate the input parameters, and later the model was tested with other one day runs. In that date 14,244 peppers were harvested during 12.93 hours. The average labor time of a path, the total yield simulated and the cycle time per sweet pepper of the registered data and simulated process were compared. The Israeli model was validated for a one day run of November $8^{\text {th }} 2013$ which simulated the harvest of a complete section (section 3 ) with 84 paths. At that date harvesting was 15.75 hours and 6693 peppers were harvested. The total harvest time, yield and harvest time per pepper of the simulation were compared to the data. The accuracy rates for all validations are calculated according to:

$$
\text { accuracy }=\left(1-\frac{\mid \text { model output }- \text { measured data } \mid}{\text { measured data }}\right) * 100 \%
$$

\section{Results}

\subsection{Data Analysis of the Dutch Greenhouse}

Using the data collected from the Dutch greenhouse it was possible to analyse behaviour and trends of different variables related to the harvesting process. Analyses

Table 2. Total working hours in the Dutch greenhouse in 2012-2013

\begin{tabular}{lll}
\hline Task & Time $(h)$ & $\%$ \\
\hline Harvesting & 663 & 38.6 \\
Trellising & 439 & 25.6 \\
Pruning and cutting plants & 260 & 15.1 \\
Sorting & 244 & 14.2 \\
Cleaning and maintenance & 72 & 4.2 \\
Other & 39 & 2.3 \\
\hline Total time & 1717 & 100 \\
\hline
\end{tabular}


of total working hours in 2012-2013 for all main crop handling processes (Table 2) indicated that harvest (39\%) and trellising (26\%) represent the largest fraction of total labour time, followed by pruning (15\%), sorting, and cleaning respectively.

The yield harvested during the season of 2013 (Fig. 2) teaches that the average harvested yield per path visit is $0.88 \mathrm{~kg} \mathrm{~m}^{-2}$ with a standard deviation of $0.29 \mathrm{~kg} \mathrm{~m}^{-2}$. The variability of harvested yield per path is characterized by a lognormal distribution with parameters $\mu=-0.182(S E=0.0365)$, and $\sigma=0.350(S E=0.0260)$. However, as yield is a result of crop development, weather and operational planning, a measured time series was used as model input.

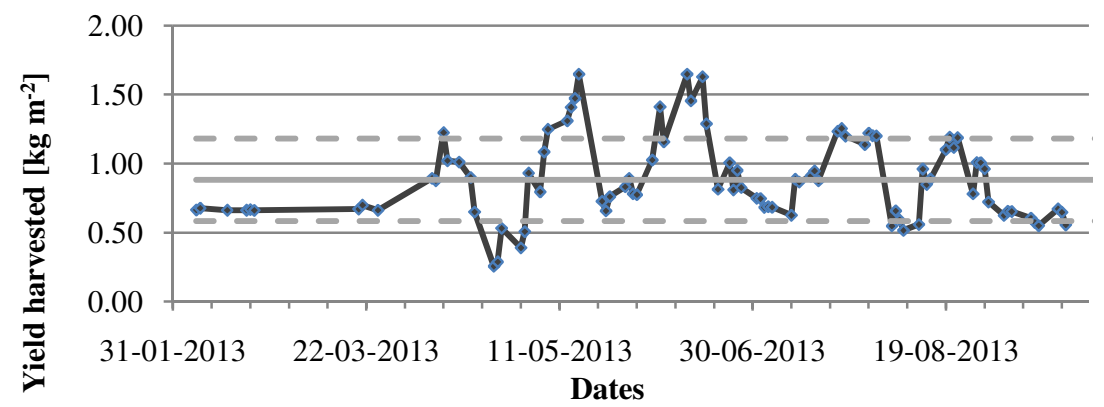

Fig. 2. The yield harvested in the Dutch greenhouse in 2013

To analyze the harvesting capabilities along the harvesting season, the relation between the path yield and the harvesting time per pepper was determined. The yield is measured, in $\mathrm{kg} \mathrm{m}^{-2}$ according to the peppers harvested on a specific day. The harvest time per pepper was calculated by:

$$
\text { Time per pepper }=\frac{\text { Total harvesting labor time in a path }}{\mathrm{kg} \text { peppers harvested/ average fruit weight }}
$$

A negative correlation between the two variables showed: as the yield in a path ( $\mathrm{x}$ ) is higher, the time to harvest each pepper (y) is lower: for $2012, \mathrm{y}=3.3261 \mathrm{x}^{-0.349}$ with $\mathrm{R}^{2}=0.6233$ and $2013, \mathrm{y}=-1.01 \ln (\mathrm{x})+3.7737$ with $\mathrm{R}^{2}=0.3268$.

\subsection{Differences between the Harvesting Process of NL and IL Greenhouses}

The harvesting process was compared by analyses of IDEF3 charts created for both greenhouses [6], [1]. Differences were studied to identify all the changes needed in order to simulate the harvesting process using the GWorkS-pepper model. The main differences are related to logistics and the order of actions, to work height adjustment, and to cutting and storing the peppers. With respect to logistics, in NL after harvesting one side of the path, the harvester turns around and harvests the other side. In IL both path sides are harvested at once. All the logistic operations on the container outside the path, is automated in NL and manual in IL. This was excluded from the simulation model due to the high variance in the manual process and low importance when 
examining the harvesting process itself (approximately 15\% of the total harvest labor time).

With respect to work height adjustment, in NL greenhouse, the harvester stays at the necessary height thanks to the electronic trolley. In IL the harvester is moving at the ground level of a path and only when necessary climbs to the appropriate height. The work height in NL is continuous within the height range of the trolley, but in IL the height of the harvester is discrete, either ground level or the height of the box. In NL, the trolley showed equal velocity for raising and lowering the platform. It was therefore defined as one action. In IL "adjusting the height" upwards takes more time than downwards. Hence, it was taken as different actions with different velocities.

With respect to cutting and storing the peppers, in NL storing the harvested peppers in a path is in one large container, but in IL there are 4-8 small boxes for that purpose. This adds another action in the harvesting process: arranging the boxes, which take place whenever a box is full, and appears to be time consuming. After cutting the pepper in IL, in some cases the harvester holds the pepper in his hands and cuts another one or two peppers. Only then the peppers are placed in the box. The probability to harvest one pepper alone is 0.79 , two peppers 0.19 and three 0.02 . In NL right after cutting it, the harvester places the pepper in the container since the container is in the ergonomic space of the harvester at all times.

Table 3. Summary of differences between the simulated Israeli and Dutch greenhouses

\begin{tabular}{|c|c|c|}
\hline Criteria & Dutch greenhouse & Israeli greenhouse \\
\hline \multicolumn{3}{|c|}{ Work methods and resources } \\
\hline Total area examined & $234 \mathrm{~m} \cdot 182.4 \mathrm{~m}$ & $96 \mathrm{~m} \cdot 100 \mathrm{~m}$ \\
\hline Paths amount & 304 & 168 \\
\hline $\begin{array}{l}\text { Amount of workers } \\
\text { before harvest } \\
\text { during harvest } \\
\end{array}$ & $\begin{array}{l}\text { 2-3 workers per hectare } \\
3-5 \text { workers per hectare }\end{array}$ & $\begin{array}{l}\text { 5-8 workers per hectare } \\
\text { 2-10 workers per hectare }\end{array}$ \\
\hline Trolleys & 36 electronic trolleys & 20 manual trolleys \\
\hline Containers & $\begin{array}{l}\text { On each trolley one container } \\
\text { with capacity of } 290 \mathrm{~kg} \text {. }\end{array}$ & $\begin{array}{l}\text { On each trolley 6-8 boxes, each } \\
\text { with the capacity of } 10 \mathrm{~kg} \text {. }\end{array}$ \\
\hline \begin{tabular}{|l|} 
Harvesting working process \\
\end{tabular} & $\begin{array}{l}\text { Harvesting at one side to the } \\
\text { end and return to main aisle } \\
\text { via the other side. }\end{array}$ & $\begin{array}{l}\text { Harvesting both sides of the } \\
\text { path in one pass. }\end{array}$ \\
\hline \multicolumn{3}{|c|}{ Numeric data base on season's databases } \\
\hline \begin{tabular}{|l|} 
Harvesting season examined \\
\end{tabular} & $\begin{array}{l}12-03-2012 \text { to } 29-10-2012 \\
8 \text { month }\end{array}$ & $\begin{array}{l}12-07-2013 \text { to } 15-02-2014 \\
7 \text { month }\end{array}$ \\
\hline Average yield all season & $30.0 \mathrm{~kg} \mathrm{~m}^{-2}$ & $18.5 \mathrm{~kg} \mathrm{~m}^{-2}$ \\
\hline \begin{tabular}{|l|l|}
$\begin{array}{l}\text { Average yield harvesting } \\
\text { day }\end{array}$ & \\
\end{tabular} & $0.8 \mathrm{~kg} \mathrm{~m}^{-2}$ & $0.6 \mathrm{~kg} \mathrm{~m}^{-2}$ \\
\hline Time per pepper & 3.89 seconds & 8.90 seconds $* *$ \\
\hline
\end{tabular}

**estimated and not definite (Taken from IL database from 2010-2011) 


\subsection{Validation Results}

Model validation was performed as a one day run for a pre-defined part of the greenhouse. The NL validation results (Table 4) in $92.1 \%$ accuracy levels of the simulated yield (with $89 \%$ standard deviation). The average labor time per path accuracy is $91.9 \%$ and cycle time per unit is around $98 \%$. The accuracy of standard deviation labor time (43.1\%) and time per unit (84\%) shows that the model has high variation between the different paths. Reality shows even stronger stochastic effects than the model. The data of IL (Table 5) does not include detailed information for each path, therefore only the following parameters were examined: sum of yield, total labor time and average cycle time per unit. The model simulates the reality of the net house at the accuracy levels of $85-95 \%$.

For both Table 4 and Table 5, model accuracy is indicated as the ratio between simulated mean for 10 runs and measured result (according to equation (1)). The 95\% confidence level for the simulated mean is indicated in brackets $( \pm \mathrm{ci})$.

Table 4. Results of a 1 day simulation of 25 paths in NL greenhouse on September 26th, 2012

\begin{tabular}{l|lcrrr}
\hline \# & Parameters & LRS dataSimulated & mean $( \pm$ ci) & Accuracy \\
\hline $\mathbf{1}$ & Sum yield $[\mathrm{u}]$ & 14244 & 16084 & $( \pm 198)$ & $92.1 \%$ \\
$\mathbf{2}$ & Standard deviation yield $[\mathrm{u}]$ & 161.2 & 207.1 & $( \pm 20.1)$ & $89.0 \%$ \\
$\mathbf{3}$ & Average labor time per path $[\mathrm{s}]$ & 1862 & 2076 & $( \pm 27)$ & $91.9 \%$ \\
$\mathbf{4}$ & Standard deviation labor time $[\mathrm{s}]$ & 570.6 & 362.3 & $( \pm 37.4)$ & $43.1 \%$ \\
$\mathbf{5}$ & Average cycle time per unit $[\mathrm{s}]$ & 3.27 & 3.34 & $( \pm 0.03)$ & $97.7 \%$ \\
$\mathbf{6}$ & Standard deviation time per unit $[\mathrm{s}]$ & 0.43 & 0.41 & $( \pm 0.03)$ & $84.0 \%$ \\
\hline
\end{tabular}

Table 5. Results of a 1 day simulation of the IL net house on November 8th, 2013

\begin{tabular}{c|lcccc}
\hline$\#$ & \multicolumn{1}{|c}{ Parameters } & Grower's data & Simulated & mean $( \pm$ ci) & Accuracy \\
\hline $\mathbf{1}$ & Sum yield $[\mathrm{u}]$ & 6693 & 7272 & $( \pm 41)$ & $91.3 \%$ \\
$\mathbf{2}$ & Total labor time $[\mathrm{s}]$ & 56700 & 54201 & $( \pm 372)$ & $95.6 \%$ \\
$\mathbf{3}$ & Average cycle time per unit $[\mathrm{s}]$ & 8.47 & 7.46 & $( \pm 0.05)$ & $88.0 \%$ \\
\hline
\end{tabular}

\section{Conclusions}

The manual sweet pepper harvesting process is now modelled in a discrete event simulation model. The model was validated for two different greenhouses and can be used for other greenhouses and crops when needed, as the model was already successfully applied for cut roses [13]. The results of the one day simulation showed that the model estimates harvesting time with an accuracy of $92 \%$ for NL data and $96 \%$ for IL data. The simulation model can be used for sensitivity analysis of parameters, to examine changes in complex work processes and is planned as a basis for a model to optimize work-methods of a sweet pepper robotic harvester under development [8] that will work cooperatively with human harvesting. 
Acknowledgements. This research was funded by the European Commission in the 7th Framework Program (CROPS GA no. 246252) and partially supported by the ABC Robotics Center funded by Helmsley Charitable Trust and by the Rabbi W. Gunther Plaut Chair in Manufacturing Engineering, both at Ben-Gurion University of the Negev.

\section{References}

1. Aantjes, G.W.J.: Data analysis and simulation trials of harvest in sweet pepper. Unpublished BSc thesis, Wageningen UR, Wageningen, The Netherlands (2014)

2. Bac, C.W., Edan, Y., Hemming, J., Van Henten, J.E.: Harvesting robots for high-value crops: state-of-the-art review and challenges ahead (in press, 2014)

3. Bechar, A., Lanir, T., Ruhrberg, Y., Edan, Y.: Improvement of work processes in gypsophila flowers. In: EFITA Conference 2009 (2009)

4. Bechar, A., Edan, Y., Krause, M.: Improvement of work methods in pepper greenhouses. In: XXXI CIOSTA-CIGR V Congress Proceedings, Hohenheim, Germany, September 19-21, pp. 249-255 (2005)

5. Bechar, A., Yosef, S., Netanyahu, S., Edan, Y.: Improvement of work methods in tomato greenhouses using simulation. Transactions of the ASABE 50(2), 331-338 (2007)

6. Elkoby, Z.: Analysis of Harvesting in Sweet Pepper Greenhouses for Human-Robot Collaboration. Unpublished BSc final project, Dept. of Industrial Eng. and Mngmt., Ben-Gurion University of the Negev, Beer-Sheva, Israel (2014)

7. Globerson, S.: Operations management and performance improvement. Dionon Publication (2002)

8. Hemming, J., Bac, C.W., van Tuijl, B.A.J., Barth, R., Bontsema, J., Pekkeriet, E., van Henten, E.: A robot for harvesting sweet-pepper in greenhouses. In: Proceedings of International Conference of Agricultural Engineering, Zurich, Switzerland (2014)

9. Law, A.M.: How to build valid and credible simulation models. Paper presented at the Proceedings of the 40th Conference on Winter Simulation, pp. 39-47 (2008)

10. Melman, N., Dotan, H.: Pepper harvesting as a case study for examinating the OLbserverxt software for work study. Unpublished BSc final project, Dept. of Industrial Eng. \&Mngmt., Ben-Gurion University of the Negev, Beer-Sheva, Israel (2014)

11. van 't Ooster, A., Bontsema, J., van Henten, E.J., Hemming, S.: GWorkS - A discrete event simulation model on crop handling processes in a mobile rose cultivation system. Biosystems Engineering 112(2), 108-120 (2012)

12. van 't Ooster, A., Bontsema, J., van Henten, E. J., Hemming, S.: Simulation of harvest operations in a static rose cultivation system. Biosystems Engineering 120, 36-46 (2014)

13. van't Ooster, A., Bontsema, J., van Henten, E. J., Hemming, S.: Sensitivity analysis of a stochastic discrete event simulation model of harvest operations in a static rose cultivation system. Biosystems Engineering 116(4), 457-469 (2013) 